\title{
Access to antiretroviral treatment among French HIV infected injection drug users: the influence of continued drug use
}

M P Carrieri, J P Moatti, D Vlahov, Y Obadia, C Reynaud-Maurupt, M Chesney, and the MANIF 2000 Study Group

\begin{abstract}
Study objective-To determine the influence of continued drug use and its perception by prescribing physicians on access to antiretroviral treatment among French HIV infected injection drug users (IDUs). Design-Cross sectional including enrolment data (October 1995-1996) of the cohort study MANIF 2000. Access to treatment is compared in three groups: former IDUs $(n=68)$ and active IDUs whether or not this behaviour remains undetected $(n=38)$ or detected $(n=17)$ by physicians.
\end{abstract}

Setting-Hospital departments for specialist AIDS care in south eastern France and inner suburbs of Paris.

Patients-All enroled patients with $\mathrm{CD}^{+}$ cell counts $<400$ with detailed clinical history, access to treatment, risk behaviours, and past drug use as reported by both physicians and patients $(n=123)$.

Main results-A minority (43.9\%) already received an antiretroviral treatment. Active IDUs had worst socioeconomic and psychological conditions but only those detected by physicians were considered as poorly compliant. Logistic regression showed that, with respect to ex-IDUs and independently of clinical stage, active IDUs, whether or not they were perceived as such by physicians, were threefold more likely not to receive antiretroviral treatment.

Conclusions-Even among French HIV infected IDUs who have regular access to AIDS specialised hospital care, continued drug use reduced the likelihood of being prescribed antiretroviral treatment. To reduce delays in access to new treatments, specific efforts must be devoted towards both AIDS specialists and IDU patients to overcome current stereotypes of noncompliance associated with continued injection.

(F Epidemiol Community Health 1999;53:4-8)

Socioeconomic differences have been observed to be strongly associated with access to newly introduced treatments for a variety of diseases, reflecting non-financial, as well as financial barriers to care. It is well established that injection drug users (IDUs) tend to have less access to care for HIV infection in general and to antiretroviral medication in particular than other groups of transmission. ${ }^{1-3}$ Inadequate health care insurance coverage is of course related with unmet health care needs of HIV infected people, ${ }^{45}$ but important inequities in utilisation of HIV health care services still exist even when free or low cost public sector care is available. $^{67}$

The French Social Security system guarantees health care insurance coverage for the whole population and since 1993, all medical care is totally free of charge as soon as a patient has a diagnosis of HIV infection. Importance of non-financial barriers to HIV care, such as the impact of injection drug use on physicians' judgments about compliance of patients, may therefore be easier to evaluate in the French context.

The MANIF 2000 French cohort study of patients HIV infected through intravenous drug use gave us the opportunity to study the determinants of access to antiretroviral treatment according to perception of patient's drug use by prescribing physicians. The study was carried out before the introduction of new treatments with protease inhibitors in this population, but current recommendations for early initiation of multiple combination treatments ${ }^{8}$ create an increased interest for better understanding the potential role of subjective factors in slowing down access of IDUs to any antiretroviral treatments.

\section{Methods}

MANIF 2000 is a prospective study that started in October 1995 whose aim is to assess the effect of persistent misuse of drugs on progression of HIV infection among patients initially infected through injection drug use. The study enrols patients aged 18 years or more, with $\mathrm{CD} 4^{+}$cell counts $\geqslant 300 / \mathrm{mm}^{3}$ in the last visit before enrolment, with no opportunistic infections, in hospital departments of Marseilles, Nice and inner suburbs of Paris (that is, the French geographical areas with the highest proportion of IDUs among AIDS cases-more than $35 \%$ of new cases in 1996).

For each eligible patient, data collected at enrolment include a detailed retrospective clinical history based on medical records, and a medical questionnaire filled out by the hospital AIDS specialist at the end of consultation that contains, in addition to clinical information and history of antiretroviral treatment, questions about physician's opinion about current drug use by his patient; physicians' beliefs about their patient's likelihood to comply with appointments and with medications are as- 
Table 1 Demographic, lifestyle, and medical/psychiatric characteristics of injection drug users by injection status $(1=$ former, $2=$ active undetected by physicians, 3 = active detected by physicians) in the French IDU cohort study MANIF 2000 (October 1995-October 1996)

\begin{tabular}{|c|c|c|c|c|c|c|}
\hline & \multirow{2}{*}{$\begin{array}{l}\text { Group } 1 \\
-- \\
(n=68)\end{array}$} & \multicolumn{2}{|c|}{$\begin{array}{l}\text { Group } 2 \\
+- \\
(n=38)\end{array}$} & \multicolumn{2}{|c|}{$\begin{array}{l}\text { Group } 3 \\
++ \\
(n=17)\end{array}$} & \multirow{2}{*}{$\begin{array}{l}\begin{array}{l}\text { Total } \\
(n=123)\end{array} \\
\%\end{array}$} \\
\hline & & $\%$ & OR $95 \% C I$ & $\%$ & OR $95 \% C I$ & \\
\hline Sex (male) & 66.2 & 68.4 & $1.1(0.4,2.8)$ & 70.6 & $1.2(0.4,5.0)$ & 67.5 \\
\hline Living alone & 44.1 & 71.1 & $3.1(1.2,8.0)$ & 52.9 & $1.4(0.4,4.7)$ & 53.7 \\
\hline Level of education ( $\geqslant$ high school certificate) & 19.1 & 7.9 & $0.4(0.1,1.5)$ & 17.6 & $0.9(0.2,4.0)$ & 15.4 \\
\hline Living on welfare & 51.5 & 78.9 & $3.5(1.3,9.8)$ & 88.2 & $7.1(1.4,67.1)$ & 65.0 \\
\hline In maintenance drug abuse treatment ${ }^{1}$ & 11.8 & 47.4 & $6.7(2.3,20.2)$ & 43.8 & $5.8(1.5,24.1)$ & 27.0 \\
\hline Poor housing conditions & 11.8 & 28.9 & $3.1(1.0,9.5)$ & 35.3 & $4.1(1.0,16.7)$ & 20.3 \\
\hline Has been institutionalised & 45.6 & 60.5 & $1.8(0.8,4.4)$ & 52.9 & $1.3(0.4,4.4)$ & 51.2 \\
\hline Follow up in hospital $(>5 \mathrm{y})^{1}$ & 50.7 & 32.4 & $0.5(0.2,1.2)$ & 29.4 & $0.4(0.1,1.4)$ & 42.1 \\
\hline Time from HIV diagnosis $(>5 \mathrm{y})$ & 81.0 & 57.9 & $0.3(0.1,0.9)$ & 58.8 & $0.3(0.1,1.2)$ & 70.7 \\
\hline CDC stage $B$ & 44.1 & 44.7 & $1.0(0.4,2.5)$ & 64.7 & $2.3(0.7,8.5)$ & 47.2 \\
\hline Antecedents of PCP prophylaxis ${ }^{1}$ & 20.6 & 18.9 & $0.9(0.3,2.7)$ & 17.6 & $0.8(0.1,3.6)$ & 19.7 \\
\hline Referred to a psychiatrist ${ }^{1}$ & 6.0 & 45.9 & $13.4(3.7,59.3)$ & 31.3 & $7.2(1.3,40.9)$ & 21.7 \\
\hline Referred to a social worker ${ }^{1}$ & 6.0 & 37.8 & $9.6(2.6,43.1)$ & 37.5 & $9.5(1.8,52.1)$ & 20.0 \\
\hline Poor compliance with medications ${ }^{\star 2}$ & 23.1 & 37.8 & $2.0(0.8,5.4)$ & 93.3 & $46.7(5.9,2011)$ & 36.8 \\
\hline Poor compliance with appointments ${ }^{\star 1}$ & 17.9 & 29.7 & $1.9(0.7,5.5)$ & 82.4 & $21.4(4.7,127)$ & 30.6 \\
\hline Satisfied with relationship to medical staff ${ }^{\star}$ & 58.8 & 71.1 & $1.7(0.7,4.4)$ & 68.8 & $1.5(0.4,6.3)$ & 63.9 \\
\hline Poor compliance with medical prescription ${ }^{1}{ }^{1}$ & 33.8 & 43.2 & $1.5(0.6,3.7)$ & 31.2 & $0.9(0.2,3.2)$ & 36.4 \\
\hline Satisfied with current state of health $\dagger$ & 83.8 & 63.2 & $0.3(0.1,0.9)$ & 62.5 & $0.3(0.1,1.2)$ & 74.6 \\
\hline Depressed $\ddagger$ & 44.1 & 84.2 & $6.8(2.3,22.1)$ & 76.5 & $4.1(1.1,18.8)$ & 61.0 \\
\hline Low social support $₫$ & 31.3 & 39.4 & $1.4(0.5,3.7)$ & 66.7 & $4.4(1.2,18.1)$ & 38.3 \\
\hline
\end{tabular}

^Physicians' declaration that patients are "never" or "rarely" compliant. †Patient’s self perception that they are "never" or "rarely" compliant. $\ddagger$ Patients with possible depression (scores $>17$ in French version of CES-D). SPatients who declare "not at all" or "only a little" support from family members, partners, and friends in everyday life. ${ }^{1}$ For these variables, $1-3$ patients did not answer the question. ${ }^{2} 6$ patients did not answer the question.

sessed by means of two questions using a five point scale (never/rarely/sometimes/often/ always). In parallel, in depth data about patient's social and psychological characteristics as well as their personal experience with HIV infection and care are obtained by means of a face to face questionnaire administered by a nurse and a self administered questionnaire. This latter questionnaire includes, among different psychometric scales, the French version of the Center for Epidemiological Studies-Depression Scale (CES-D), ${ }^{9}{ }^{10}$ three questions about patient's perceived social support in current daily life by partner, family and friends (using four point scales: not at all/ only a little/ fairly/very important), and patients' self perception of compliance with medical prescriptions (using the same five point scale as in the physician's questionnaire). It also contains 19 questions about HIV related risk behaviours including type of drug use, frequency of injection, and access to drug maintenance treatment during lifetime and the last six months.

To assess the impact of active drug use and its perception by physicians on access to antiretroviral treatment, we examined patients and physicians' answers about current drug use and classified patients into three categories: those who declared that they did not inject any drug in the last six months and were concordingly perceived as abstinent by their physician (group 1); those who acknowledged injecting behaviour during the same period but were discordantly perceived as abstinent by their physician (group 2); those who were considered as active IDUs by physicians (group 3 ).

A total of 325 patients were recruited in the first year of the study (October 1995-October 1996). Determinants of access to antiretroviral treatment were evaluated in the subset of 129 patients with less than $400 \mathrm{CD}^{+}$cell counts/ $\mathrm{mm}^{3}$ at enrolment, as it is the subgroup of patients where initiation of antiretroviral treat- ment has to be considered according to official French clinical guidelines. ${ }^{11}$

Mann-Whitney or $\chi^{2}$ tests were used for comparing characteristics of patients in the three groups and for identifying variables likely to be related to access to antiretroviral treatment. Odds ratios and their 95\% confidence intervals were calculated to quantify the strength of association. To examine the hypothesis that continued drug use and its perception by physicians influences prescription of antiretroviral drugs, even after adjustment for clinical and psychosocial variables also related to access to treatment in univariate analyses $(\mathrm{p}<0.05)$, multiple logistic regression models were performed.

\section{Results}

Among the 129 patients with $\mathrm{CD} 4^{+}$cell counts $<400 / \mathrm{mm}^{3}$, six could not be classified for current drug use because of missing data and were subsequently excluded from the analysis. The remaining 123 patients were classified as follows: (1) A total of 71 patients declared being abstinent of injection drug use, and only three were discordantly considered as active injectors by the physician. Group 1 (abstinent perceived as such by physicians) therefore includes 68 patients. (2) Another group of 52 patients reported having injected drugs during the last six months. But 38 of them were not considered as such by the physician's judgment and formed group 2 (active IDUs not perceived as active by physicians). (3) Group 3 (patients considered as active by physicians) consisted of 17 patients: 14 patients who acknowledged current injection drug use and three patients who did not. It must be noted that for these three patients, physicians' questionnaires mentioned clinical signs of recent injection drug use.

When comparing medians and interquartile ranges in the three groups of patients $(1,2,3)$, no significant differences were found as far as 
age, (32 (30.2-36.0); 33 (30.0-36.0); 34 (30.0-37)) time since last visit before enrolment, (2 months (1-4); 2 (1-5.5); 2 (1-3.5)), $\mathrm{CD} 4{ }^{+}$cell counts $/ \mathrm{mm}^{3}$ at enrolment (329 (270$358) ; 321$ (290-360); 300 (262-346)), and plasma viral load $(\log \mathrm{cp} / \mathrm{ml})$ (4.3 (3.4-4.8); 4.2 (3.6-4.8); $4.4(3.8-4.7))$. Patients who stopped injection had shorter periods $(\mathrm{p}<0.05)$ of drug use during lifetime (8 years (4-11) v 14 (11-17) and $15.5(6.5-16.7))$.

Table 1 shows that the three groups had similar distribution by sex, CDC stage, education level, experiences of imprisonment, years of follow up at the hospital, years from initial HIV diagnosis, and antecedents of pneumocystis carinii pneumonia (PCP) prophylaxis, suggesting that they did not generally differ in terms of access to health care. Table 1 also shows that active IDUs (groups 2 and 3), whether or not they were recognised as such by physicians, had worse socioeconomic conditions, were more depressed and unsatisfied by their current health status than those who had stopped injecting drugs (group 1). Active IDUs were also more likely to have been referred to a specialist for psychiatric or anxiety disorders, and to social workers for support during the last six months. Table 1 also shows that physicians clearly distinguish IDUs that they identify as such (group 3) and the rest of the sample in terms of poor compliance. Physicians' perceptions contrast with patients' declarations about compliance and satisfaction with medical staff, which are similar in the three groups.

A minority $(n=54 ; 43.9 \%)$ of patients already benefited from a prescription of antiretroviral treatment. Among the 49 treated patients where detailed information about past treatment was available, $30(61.2 \%)$ received a combination therapy with two or more reverse transcriptase inhibitors and $15(30.6 \%)$ had their antiretroviral treatment started during the last 12 months. No significant difference for duration of antiretroviral treatment was observed between treated IDUs and ex-IDUs. At the time of data collection (October 1995October 1996), no protease inhibitor had yet been prescribed to any patient.

Advanced CDC stage, living in a stable relationship with a partner, and abstinence of drug use were the only variables to be significantly associated with receiving antiretroviral treatment. Multiple logistic regression (table 2) shows that, after accounting for CDC AIDS staging system, former IDUs were three times more likely to receive antiretroviral drugs than
KEY POINTS

- Socioeconomic differences have often been observed in access to new treatments and related to financial and non-financial barriers.

- Since 1993, the French social security system guarantees a free of charge access to health care for all HIV infected persons.

- The cohort MANIF 2000 can show how continued drug use among HIV infected persons can influence access to antiretroviral treatment in the absence of financial barriers.

- Results call for actions towards both AIDS specialists and IDUs for overcoming sterotypes of non-compliance associated with continued injection.

active IDUs whether or not the latter were labelled as such by physicians (groups 3 and 2).

\section{Discussion}

HIV infected IDUs who continue to use drugs tend to have a lower access to medical care, and a lower frequency of clinical encounters than those who stopped injecting behaviour ${ }^{2}{ }^{3}$; in the US HIV infected IDUs have been found to be more likely to use informal unpaid home care than other patients. ${ }^{12}$ As a consequence continued drug use is likely to be associated with lower access to antiretroviral treatment.

The French context allowed us to check the impact of continued drug use on access to antiretroviral treatment when financial barriers to HIV care in general do not exist. Our data strongly show that even among French HIV infected IDUs who had regular access to AIDS specialised hospital care, with similar medical conditions (in terms of clinical stage, levels of $\mathrm{CD}^{+}$cell counts, and plasma viral load) and similar duration of medical follow up, those who continue to inject drugs were less likely to benefit from antiretroviral treatment.

Of course, it cannot be excluded that, in our study, some active IDUs have been offered antiretroviral treatment but have declined this opportunity more often than ex-IDUs. Our data, however, suggest that physicians' perceptions of patients' behaviours influence their decision to start antiretroviral treatment and that continued drug use, whether or not it is explicitly recognised in the patient-physician relationship, is associated with greater physi-

Table 2 Factors associated with access to antiretroviral treatment in HIV infected injection drug users with

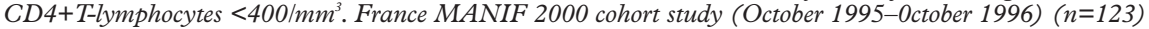

\begin{tabular}{llll}
\hline & $\%$ Treated & OR and $95 \% C I$ & Adjusted OR and $95 \% C I$ \\
\hline $\begin{array}{l}\text { CDC AIDS staging } \\
\quad \text { stage A }\end{array} \quad 29.2$ & 1 & \\
$\quad$ stage B & 51.7 & $2.59(1.16,5.85)$ & $2.84(1.31,6.17)$ \\
$\quad$ Living in a stable relationship & & & \\
$\quad$ No & 30.3 & 1 & - \\
$\quad$ Yes & 50.9 & 1 & \\
Injection status & 47.1 & $0.52(0.21,1.29)$ & $0.36(0.15,0.85)$ \\
1 Former IDU & 31.6 & $0.47(0.12,1.64)$ & $0.26(0.08,0.87)$ \\
2 Active IDU undetected by physicians & 29.4 & & \\
3 Active IDU detected by physicians & &
\end{tabular}


cian's reluctance to start antiretroviral prescription.

Despite the adherence of physicians to a universal code of ethics, discriminatory attitudes toward HIV infected patients have been well documented among health care professionals, ${ }^{13}{ }^{14}$ and such attitudes are exacerbated where these patients are IDUs. ${ }^{15-17}$ However, it is also well established that discriminatory biases quickly decline as health professionals become familiar with treating people with HIV. ${ }^{18-20}$ Our data did not report whether or not discriminatory attitudes may have persisted among AIDS specialists in the hospital departments participating in our study.

They show in any case that the subjective judgments of doctors about the poor personal and social environment and anticipation of poor compliance of patients, which may be based on previous experience in clinical interaction, influence their decisions to withhold antiretroviral treatment among HIV infected patients who continue to use drugs.

The fact that active IDUs, who are not seen as active anymore by their physicians, also remain less likely to receive antiretroviral treatment than actual former users, suggest that clinicians tend to make judgments based upon perceived chaotic lifestyles, even in the absence of perceived injection drug use. These judgments are partly based on real conditions: not surprisingly those who continue to use drugs remain in the worst social and psychological conditions, which create additional difficulties for continuity of care. ${ }^{21-23}$ Such situations can raise legitimate concerns among physicians about the capacity of patients to comply to treatment, and risks of developing drug resistance that could be harmful for the long term management of the patient himself as well as others in case of HIV transmission.

However, it has also been shown that HIV infected health seeking behaviours are directly influenced by their perception of health care professional attitudes. Recent progress in antiretroviral treatment makes an obligation for professionals to revisit the stereotype of noncompliant and non-reliable IDU patients. ${ }^{24-26}$ After all, the extent to which IDUs have already changed their behaviour to reduce risk of AIDS worldwide has been impressive going well beyond what most medical experts in the field would have predicted. ${ }^{27}$

Introduction of protease inhibitors may change this differential access to treatment according to current status toward drug use. But to the extent that non-compliance has been clearly linked to viral resistance and drug failure in the case of antiprotease inhibitors, ${ }^{28}$ it is quite possible that persistence of injecting drug use will create a barrier for rapid access to these new treatments, unless specific efforts are devoted for improving the quality of relationships between AIDS specialists and their IDU clients and for increasing appropriate social and psychological support to this group of HIV infected patients.

Successful AIDS/HIV risk reduction intervention among IDUs most usually have several components including outreach work and peer education targeted for their social networks. ${ }^{29}$ Interventions aimed at increasing IDUs access and compliance to multiple combination therapies will certainly have to be based on similar principles, but our study suggests that these types of interventions targeted at IDUs in their social environment could be usefully complemented by other actions towards both AIDS specialists and IDU patients for overcoming current stereotypes of non-compliance associated with continued injection.

The MANIF 2000 cohort study is supported by the French National Agency for AIDS Research (ANRS) and the charity organisation SIDACTION.

organisation SIDACTION.

1 Crystal S, Sambamoorthi U, Merzel C. The diffusion of innovation in AIDS treatment : zidovudine use in two New innovation in AIDS treatment : zidovudine use in

2 Hu DJ, Byers R Jr, Fleming PL, et al. Characteristics of persons with late AIDS diagnosis in the United States. Am F Prev Med 1995;11:114-19.

3 Tramarin A, Campostrini S, Tolley K, et al. The influence of socioeconomic status on health service utilisation by patients with AIDS in North Italy. Soc Sci Med 1997;45: $859-66$

4 Katz MH, Chang SW, Buchbinder SP, et al. Health insurance and use of medical services by men infected with HIV. F Acquir Defic Syndr Hum Retrovirol 1995;8:58-63.

5 Bonuck KA, Arno PS, Green J, et al. Self-perceived unmet health care needs of persons enrolled with HIV care. $\mathcal{F}$ Community Health 1996;21:183-98.

6 Kissinger P, Cohen D, Brandon W, et al. Compliance with public sector HIV medical care. F Natl Med Assoc 1995;87: pu-24.

7 Mercey D, Griffioen A, Woronowski H, et al. Uptake of medical interventions in women with HIV infection in medical interventions in women with HIV infection

8 Carpenter CC, Fischl MA, Hammer SM, et al. Antiretroviral therapy for HIV infection in 1996. Recommandations of an international panel. International AIDS Society-USA. fAMA 1996;276:146-54.

9 Radloff LS. The CES-D scale: a self-report depression scale for research in the general population. Applied Psychology Measurement 1977;3:385-401.

10 Fuhrer F, Rouillon F. La version française de l'échelle CES-D. Description et traduction de l'échelle d'autoévaluation. [In French]. Psychiatrie and Psychobiologie 1989;4:163-6.

11 Dormont J, ed. La prise en charge des personnes infectées par le Virus d'Immunodéficience Humaine. [In French]. Paris: Ministère de la Solidarité et de la Santé, 1996.

12 Ettner SL, Weissmann J. Utilisation of formal and informal home care by AIDS patients in Boston: A comparison of home care by AIDS patients in Boston: A comparison of
intravenous drug users and homosexual males. Med Care intravenous drug

13 Herek GM, Glunt EK. An epidemic of stigma: public reacions to AIDS. Am Psychol 1988;43:886-91.

14 Kelly JA, Lawrence ST, Smith S, et al. Stigmatization of AIDS patients by physicians. Am F Public Health 1987;77: 789-91

15 Crandall SC, Coleman R. AIDS-related discrimination and the disruption of social relationships. Fournal of Social and Personal Relationships 1992;9:163-77.

16 Yedidia M, Barr JK, Berry CA. Physicians'attitudes toward AIDS at different career stages : a comparison of internists and surgeons. F Health Soc Behav 1993;34:272-84.

17 Moatti J-P, Souville M, Obadia Y, et al. Ethical dilemmas in care for HIV infection among French general practitioners. Health Policy 1995;31:197-210.

18 Green G, Platt S. Fear and loathing in health care settings reported by people with HIV. Sociology of Health and Illness 1997;19:70-92.

19 Gerbert B, Maguire B, Bleecker T, et al. Primary care physicians and AIDS: attitudinal and structural barriers to care. fAMA 1991;266:2837-42.

20 Rizzo JA, Marder WD, Willk RJ. Physician contact with and attitudes toward HIV-seropositive patients: results from a national survey. Med Care 1990;28:251-60.

21 Bonuck KA, Arno PS. Social and medical factors affecting hospital discharge of persons with HIV/AIDS. 7 Community Health 1997;22:225-32.

22 Pattullo ALS, Hogg RS, Schilder A, et al. Heterogeneity of care for HIV-infected individuals decreases with the physician knowledge. Int f STD AIDS 1996;7:435-8.

23 Batki SL, Ferrando SJ. Diagnosis and treatment of substance use disorders in patients with HIV infection. International Review of Psychiatry 1996;8:245-52.

24 Crespo-Fierro M. Compliance/adherence and care management in HIV disease. $\mathcal{f}$ Assoc Nurses AIDS Care 1997;8:4354.

25 Becker MH, Maiman LA. Strategies for enhancing patient compliance. F Community Health 1980;6:113-35.

26 Breitbart W, Rosenfeld B, Passik S, et al. A comparison of pain report and adequacy of analgesic therapy in 
ambulatory-AIDS patients with and without a history of substance abuse. Pain 1997;72:235-53.

27 Des Jarlais DC, Fin $1997,72: 235-2$ effect of AIDS-related behavioral change among injection drug users. A cross-national study. Am $\mathcal{f}$ Public Health 1996;86:1780-5.
28 Deeks SG, Smith M, Holodniy M, et al. HIV-1 protease inhibitors. A review for clinicians. FAMA 1997;277:145in

29 Des Jarlais DC, Friedman SR. HIV epidemiology and interventions among injecting drug users. Int $\mathcal{F}$ STD AIDS 1996;7 (suppl 2):57-61.

\section{$\mathrm{JECH}$ and the world wide web}

Visitors to the world wide web can now access the fournal of Epidemiology and Community Health either through the BMJ Publishing Group's home page (http://www.bmjpg.com) or directly by using its individual URL (http://www.jech.com). There they will find the following:

- Current contents list for the journal

- Contents lists of previous issues

- Members of the editorial board

- Subscribers' information

- Instructions for authors

- Details of reprint services.

Hotlink

A hot link gives access to:

- BMJ Publishing Group home page

- British Medical Association website

- Online books catalogue

- BMJ Publishing Group books.

Suggestions welcome

The website is at a preliminary stage and there are plans to develop it into a more sophisticated site. Suggestions from visitors about features they would like to see are welcomed. They can be left via the opening page of the BMJ Publishing Group site or, alternatively, via the journal page, through "about this site". 